\title{
Spring emergence of Canadian Delia radicum and synchronization with its natural enemy, Aleochara bilineata
}

\author{
L.D. Andreassen, U. Kuhlmann, J.W. Whistlecraft, J.J. Soroka, P.G. Mason, \\ O.O. Akinremi, N.J. Holliday ${ }^{1}$
}

\begin{abstract}
To characterize time of spring emergence following post-diapause development, Delia radicum (L.) (Diptera: Anthomyiidae) from Saskatchewan, Manitoba, and southwestern Ontario were collected in fall, maintained over winter at $1{ }^{\circ} \mathrm{C}$, then transferred to higher constant temperatures until adult emergence. At each location there were "early" and "late" phenotypes. Truncated normal models of temperature dependency of development rate were fitted for each phenotype from each location. We provide the first evidence of geographic variation in the criteria separating these phenotypes. Separation criteria and models for early and late phenotypes at the two prairie locations, approximately $700 \mathrm{~km}$ apart, were indistinguishable, but differed from those for Ontario. Prairie phenotypes developed more slowly than Ontario phenotypes, and more prairie individuals were of the late phenotype. Poor synchronization of spring emergence could impair predation of $D$. radicum eggs by adult Aleochara bilineata Gyllenhal (Coleoptera: Staphylinidae). Aleochara bilineata from Manitoba were reared and development rates modelled as for D. radicum. Models of development rates for the two species, when combined with simulated soil temperatures for two prairie locations, suggest that emergence of adult $A$. bilineata is well synchronized with availability of $D$. radicum eggs in prairie canola.
\end{abstract}

Résumé-Afin de caractériser le moment de l'émergence printanière qui suit le développement d'après la diapause, nous avons récolté des Delia radicum (L.) (Diptera : Anthomyiidae) dans des cultures de Saskatchewan, du Manitoba et du sud-ouest de l'Ontario à l'automne, les avons conservés durant l'hiver à $1{ }^{\circ} \mathrm{C}$, puis transférés à des températures constantes plus élevées jusqu'à l'émergence des adultes. Ầ chaque site, il y avait des phénotypes " hâtif » et " tardif ». Des modèles normaux tronqués de la dépendance du taux de développement de la température ont pu être ajustés à chaque phénotype à chacun des sites. Nous présentons les premières données qui montrent une variation géographique des critères qui séparent ces phénotypes. Les critères de séparation et les modèles des phénotypes hâtifs et tardifs ne peuvent être distingués entre les sites des prairies distants d'environ $700 \mathrm{~km}$, mais ceux-ci se démarquent de ceux de l'Ontario. Les phénotypes des prairies se développent plus lentement que les phénotypes de l'Ontario et un plus grand nombre des $D$. radicum des prairies appartiennent au phénotype tardif. Une faible synchronisation de l'émergence printanière pourrait entraver la prédation des œufs de D. radicum par les adultes d'Alaeochara bilineata Gyllenhal (Coleoptera : Staphylinidae). Nous avons fait des élevages d'A. bilineata du Manitoba et modélisé leur taux de développement comme nous l'avions fait pour D. radicum. Les modèles des taux de

Received 19 June 2009. Accepted 7 December 2009.

L.D. Andreassen, N.J. Holliday ${ }^{1}$, Department of Entomology, University of Manitoba, Winnipeg, Manitoba, Canada R3T 2N2

U. Kuhlmann CABI Europe - Switzerland, 1 rue des Grillons, 2800 Delémont, Switzerland

J.W. Whistlecraft Southern Crop Protection and Food Research Centre, Agriculture and Agri-Food Canada, 1391 Sanford Street, London, Ontario, Canada N5V 4T3

J.J. Soroka Saskatoon Research Centre, Agriculture and Agri-Food Canada, 107 Science Place, Saskatoon, Saskatchewan, Canada S7N 0X2

P.G. Mason Eastern Cereal and Oilseed Research Centre, Agriculture and Agri-Food Canada, 960 Carling Avenue, Ottawa, Ontario, Canada K1A 0C6

O.O. Akinremi Department of Soil Science, University of Manitoba, Winnipeg, Manitoba, Canada R3T 2N2

${ }^{1}$ Corresponding author (e-mail: Neil_Holliday@umanitoba.ca).

doi: $10.4039 / \mathrm{n} 09-060$ 
développement des deux espèces, combinés aux températures simulées des sols de deux sites des prairies, indiquent que l'émergence des adultes d'A. bilineata est bien synchronisée avec la disponibilité des œufs de $D$. radicum dans les cultures de colza des prairies.

[Traduit par la Rédaction]

\section{Introduction}

The root-feeding species of Delia RobineauDesvoidy (Diptera: Anthomyiidae) have become more widespread and injurious to canola (oilseed cultivars of Brassica napus L. and B. rapa L. (Brassicacae)) on the Canadian prairies as the area planted has increased (Soroka et al. 2004). In regions of the prairies with more than $250 \mathrm{~mm}$ of rainfall from June to August, the cabbage maggot, $D$. radicum (L.), is the most abundant Delia species attacking canola (Griffiths 1986b).

A short photoperiod and low temperatures induce overwintering diapause in D. radicum (Hughes 1960; Read 1969) as pupae within puparia (Hughes 1960). In spring, pupae undergo post-diapause development culminating in adult emergence. Activity of adult D. radicum on the prairies peaks in early June (Bracken 1988) or mid-June (Griffiths 1986b), when females oviposit around canola roots and floral buds are raised above leaf rosettes (Griffiths 1986a). The duration of post-diapause development is temperature-dependent, but there are two types of response: individuals of the "early" phenotype complete post-diapause development within 14 days at $20^{\circ} \mathrm{C}$; emergence of adults of the "late" phenotype is delayed and protracted, with some individuals requiring 100 days at $20{ }^{\circ} \mathrm{C}$ to complete development (Finch and Collier 1983). Extended cold treatment does not induce late-phenotype individuals to commence post-diapause development more quickly after the temperature is increased to $20{ }^{\circ} \mathrm{C}$ (Finch and Collier 1983). Although Collier et al. (1989a) hypothesized that the late phenotype requires a second phase of diapause, it is now known that the traits of early and late emergence are exhibited in all pupae, regardless of their diapause state (Biron et al. 1998).

Whether a phenotype is early or late is a heritable trait (Walgenbach et al. 1993) that responds rapidly to selection (Finch and Collier 1983). Nevertheless, laboratory selection studies suggest that the early phenotype is not governed by a single dominant allele, that there are multiple loci for the late phenotype, and that these loci are expressed when the early allele is in the recessive state (Biron et al. 2002). Populations of D. radicum vary in the proportions of early and late phenotypes across North America (Walgenbach et al. 1993; Turnock and Boivin 1997) and Europe (Finch and Collier 1983; Finch et al. 1988), even when populations are separated by only a few kilometres (Finch et al. 1986).

The criterion for separating the two phenotypes has been variously defined as 224 daydegrees above $4{ }^{\circ} \mathrm{C}\left(\mathrm{DDC}_{4}\right)$ (Finch and Collier 1983), $320 \mathrm{DDC}_{4}$ (Collier et al. 1989a, 1989b), and $256 \mathrm{DDC}_{4}$ (Turnock et al. 1985; Turnock and Boivin 1997). By any of these definitions, a large proportion of individuals in $D$. radicum populations in Alberta (Broatch et al. 2006) and Manitoba (Turnock and Boivin 1997) are of the late phenotype, whereas early phenotypes predominate in southern Ontario and Quebec (Turnock and Boivin 1997), Norway (Johansen and Meadow 2006), and some parts of the English Midlands (Finch and Collier 1983). Therefore, the characteristics of the late phenotype are the most important influences on the seasonal activity of $D$. radicum in western Canada, and the damage caused to canola crops there.

Aleochara bilineata Gyllenhal (Coleoptera: Staphylinidae) is an important natural enemy of D. radicum (Read 1962; Turnock et al. 1995; Soroka et al. 2002; Hemachandra et al. 2007). Adult $A$. bilineata feed on $D$. radicum eggs and larvae, and $A$. bilineata larvae parasitize D. radicum puparia (Wadsworth 1915). Aleochara bilineata larvae overwinter in puparia, then develop more slowly to emergence at low temperatures and more quickly at high temperatures than D. radicum (Read 1962). In spring in Ontario, adult Aleochara emerged up to three weeks later than adult $D$. radicum (Nair and McEwen 1975), but which D. 
Table 1. Locations of Delia radicum puparia in Manitoba, Ontario, and Saskatchewan used for comparing post-diapause development.

\begin{tabular}{|c|c|c|c|}
\hline & Crop* & Collection date & No. collected \\
\hline \multicolumn{4}{|l|}{ 2004-2005 experiment } \\
\hline \multicolumn{4}{|l|}{ Prairie Provinces } \\
\hline Shellbrook, Sask. $\left(53^{\circ} 13^{\prime} \mathrm{N}, 106^{\circ} 23^{\prime} \mathrm{W}\right)$ & Canola & 30 Sept. -6 Oct. 2004 & 384 \\
\hline Fort Whyte, Man. $\left(49^{\circ} 49^{\prime} \mathrm{N}, 97^{\circ} 12^{\prime} \mathrm{W}\right)$ & $\begin{array}{l}\text { Rutabaga, broccoli, } \\
\text { cabbage }\end{array}$ & $8-11$ Oct. 2004 & 573 \\
\hline \multicolumn{4}{|l|}{ Southwestern Ontario } \\
\hline London $\left(42^{\circ} 59^{\prime} \mathrm{N}, 91^{\circ} 15^{\prime} \mathrm{W}\right)$ & Rutabaga & 14 Nov. 2004 & 417 \\
\hline \multicolumn{4}{|l|}{ 2005-2006 experiment } \\
\hline \multicolumn{4}{|l|}{ Prairie Provinces } \\
\hline Shellbrook, Sask. $\left(53^{\circ} 13^{\prime} \mathrm{N}, 106^{\circ} 23^{\prime} \mathrm{W}\right)$ & Canola & 29 Sept. 2005 & 375 \\
\hline Carman, Man. $\left(49^{\circ} 30^{\prime} \mathrm{N}, 98^{\circ} 00^{\prime} \mathrm{W}\right)$ & Canola & 14-31 Oct. 2005 & 385 \\
\hline \multicolumn{4}{|l|}{ Southwestern Ontario } \\
\hline London $\left(42^{\circ} 59^{\prime} \mathrm{N}, 91^{\circ} 15^{\prime} \mathrm{W}\right)$ & Rutabaga & 8 Nov. 2005 & 415 \\
\hline
\end{tabular}

*Cultivars of Brassica spp.

radicum phenotype was involved is not known, and the Aleochara were a mixture of species. Despite these uncertainties, Soroka et al. (2002) considered that poor synchronization in spring decreases the effectiveness of $A$. bilineata as a predator of $D$. radicum eggs, and recommended a search for better synchronized populations of A. bilineata. In prairie canola crops in late summer, parasitism of $D$. radicum puparia by A. bilineata larvae is also poorly synchronized: larvae are present too early to make optimal use of available hosts (Hemachandra et al. 2007). Broatch et al. (2008) suggested that A. bilineata emergence in Alberta is well synchronized with Delia oviposition; however, this conclusion was based on emergence in plots subjected to prolonged caging, which can affect microclimate and time of emergence (Southwood and Siddorn 1965).

The objectives of this research were to compare the response to temperature of rates of post-diapause development of $D$. radicum in populations from Manitoba, Saskatchewan, and southern Ontario and to determine whether poor synchronization can impair predation of $D$. radicum eggs by $A$. bilineata in prairie Canada. First, cold-exposed samples of diapausing pupae were reared at constant temperature, and nonlinear regression modelling was used to test for phenotypic differences among populations. Then, to assess the degree of synchrony of the predator with the availability of prey eggs, the regression models and simulated soil temperatures were combined to allow the dates of spring emergence of $D$. radicum and $A$. bilineata at prairie locations, one each in Manitoba and Saskatchewan, to be predicted.

\section{Materials and methods}

\section{Collection of development-rate data}

In 2004-2005 and 2005-2006, individuals from three $D$. radicum populations and one A. bilineata population were exposed to different temperature regimes to assess post-diapause development rates. Larvae and puparia of $D$. radicum were collected from the field at three locations in the fall of both 2004 and 2005, at a time when diapause was assumed to have been induced. Delia radicum larvae were fed slices of rutabaga (a cultivar of B. napus) until they formed puparia. In the 2004-2005 experiment, $D$. radicum were collected from near Shellbrook, Saskatchewan, Fort Whyte, Manitoba, and London, Ontario (Table 1), and puparia were buried individually in $14 \mathrm{~mL}$ plastic vials half-filled with sand and vermiculite and maintained at $7 \pm 0.5^{\circ} \mathrm{C}$ with no light until all experimental material was assembled. Individuals from each population were then subjected to a cold treatment at $1 \pm 0.5{ }^{\circ} \mathrm{C}$ for 16 weeks. One week before the end of cold treatment, the depth of substrate was reduced 
to about $5 \mathrm{~mm}$ to facilitate detection of emerging adults. In the 2005-2006 experiment, D. radicum were collected from near Carman, Manitoba, Shellbrook, and London (Table 1), and were all maintained at $1 \pm 0.5^{\circ}$ for 22 weeks. The same vials were used as in 2004 2005 , but puparia were placed at $1{ }^{\circ} \mathrm{C}$ after collection or as they were formed; the volume of substrate was not reduced.

In both years, $A$. bilineata from a laboratory colony originating from collections made near Anola, Manitoba $\left(49^{\circ} 53^{\prime} \mathrm{N}, 96^{\circ} 38^{\prime} \mathrm{W}\right)$, in 2002 were induced to diapause by exposing larvae to diapausing $D$. radicum puparia for 18-21 days at $14{ }^{\circ} \mathrm{C}$ with no light (Whistlecraft et al. 1985). Puparia containing A. bilineata were exposed to the same conditions as $D$. radicum except that in 2005-2006, half the A. bilineata were kept at $1{ }^{\circ} \mathrm{C}$ for 12 weeks and the other half for 22 weeks.

In both 2004-2005 and 2005-2006, following cold treatment, insects from each of the four populations were divided into groups of equal size and one group was assigned to each of five temperature regimes. Emergence was checked daily. In the 2004-2005 experiment the vials were moved from $1{ }^{\circ} \mathrm{C}$ to the treatment temperatures in $5^{\circ} \mathrm{C}$ steps every 2 days. The final temperatures in 2004-2005 were 13.0, 16.0, 19.0, 22.0, and 24.0 $\pm 0.5^{\circ} \mathrm{C}$. In the 2005-2006 experiment, insects were moved directly from $1{ }^{\circ} \mathrm{C}$ to treatment temperatures 8.2, 12.2, 14.6, 17.0, and $20.0 \pm 0.5$ ${ }^{\circ} \mathrm{C}$, and the $A$. bilineata were divided into 10 groups, 1 group for each temperature treatment after 12 or 22 weeks at $1{ }^{\circ} \mathrm{C}$. All experiments were carried out in environmental chambers with a 16L:8D photoregime.

Voucher specimens from each population were identified to species (Brooks 1951; Griffiths 1991) and deposited in the J.B. Wallis Museum of Entomology at the University of Manitoba.

\section{Analysis of development-rate data}

The relationship between development rate and temperature for the 2005-2006 experiment was fitted to Taylor's (1981) truncated normal model:

$$
R(T)=R_{m} e^{\left[-\frac{1}{2}\left(\frac{T-T_{m}}{T_{\sigma}}\right)^{2}\right]}
$$

where $R(T)$ is the development rate (1/days) at temperature $T\left({ }^{\circ} \mathrm{C}\right), R_{\mathrm{m}}$ is the maximum development rate, which occurs at temperature $T_{\mathrm{m}}$, and $T_{\sigma}$ describes the spread of the normal curve. The simple model, shown above, was estimated for $A$. bilineata and compared with a model with separate parameters for beetles that spent 12 or 22 weeks at $1{ }^{\circ} \mathrm{C}$. For $D$. radicum, the 2005-2006 data were used to estimate the parameters of a model that assigned the three populations different criteria, or "breakpoints" ( $B$, measured as $\left.\mathrm{DDC}_{4}\right)$, to separate the early and late phenotypes; different parameter values $\left(R_{\mathrm{m}}, T_{\mathrm{m}}, T_{\sigma}\right)$ for the two phenotypes; and different parameters for the two phenotypes in the three populations. The full model, therefore, was

$$
\begin{aligned}
R(T) & =\left\{\left(R_{m l E} e^{\left[-\frac{1}{2}\left(\frac{T-T_{m l E}}{T_{\sigma l E}}\right)^{2}\right]}\right)\left(D D C_{4} \leq B_{l}\right)\right\} \\
& +\left\{\left(R_{m l L} e^{\left[-\frac{1}{2}\left(\frac{T-T_{m l L}}{T_{\sigma L L}}\right)^{2}\right]}\right)\left(D D C_{4}>B_{l}\right)\right\} \\
+ & \left\{\left(R_{m s E} e^{\left[-\frac{1}{2}\left(\frac{T-T_{m s E}}{T_{\sigma s E}}\right)^{2}\right]}\right)\left(D D C_{4} \leq B_{s}\right)\right\} \\
+ & \left\{\left(R_{m s L} e^{\left[-\frac{1}{2}\left(\frac{T-T_{m s L}}{T_{\sigma s L}}\right)^{2}\right]}\right)\left(D D C_{4}>B_{s}\right)\right\} \\
+ & \left\{\left(R_{m c E} e^{\left[-\frac{1}{2}\left(\frac{T-T_{m c E}}{T_{\sigma c E}}\right)^{2}\right]}\right)\left(D D C_{4} \leq B_{c}\right)\right\} \\
+ & \left\{\left(R_{m c L} e^{\left[-\frac{1}{2}\left(\frac{T-T_{m c L}}{T_{\sigma c L}}\right)^{2}\right]}\right)\left(D D C_{4}>B_{c}\right)\right\}
\end{aligned}
$$

where the parameter $R_{\mathrm{m} i j}$ is for the $i$ th population ( $l$ is London, $s$ is Shellbrook, $c$ is Carman) and $j$ th phenotype ( $E$ is early, $L$ is late), and terms of the form $\left(\mathrm{DDC}_{4}>B_{i}\right)$ return a value of 1 when true and 0 when false.

Breakpoints were initially estimated for each population individually and, because 
the distribution of $\mathrm{DDC}_{4}$ values was discontinuous and non-integrable, manual iteration was used to estimate the most appropriate breakpoint for each population within the $\mathrm{DDC}_{4}$ range 200-320, including $256 \mathrm{DDC}_{4}$ (Turnock and Boivin 1997), $320 \mathrm{DDC}_{4}$ (Collier et al. 1989a), and $224 \mathrm{DDC}_{4}$ (Finch and Collier 1983). An $F$-ratio test of error mean squares was used to determine whether including separate parameters and breakpoints for the different populations significantly improved the fit of the model (Gallant 1987). The fit of the final model was assessed by using the meancorrected $r^{2}$ to assess the proportion of amonggroups sums of squares explained by the model (Kvalseth 1985; Sokal and Rohlf 1995), where groups were all combinations of temperature, source population, and phenotype for D. radicum and all combinations of temperature and overwintering treatment for A. bilineata. Lamb's (1992) methods of estimating developmental-threshold temperature and day-degree requirement were followed.

Model effectiveness was tested by comparing median observed days to emergence with those predicted by the model, using linear regression and by examining the mean-corrected multiple $r^{2}$. Data from the 2004-2005 experiment could not be directly fitted to a model because of the complexity introduced by the stepped temperature increase, therefore they were analyzed by first estimating the proportion of development that occurred as the insects were gradually brought to the final treatment temperatures, using the appropriate parameters derived from the 20052006 experiment. The estimated development rate was used to predict days to emergence at the final temperature, which was then regressed on the observed median number of days. If the calculated intercept was not significantly different from 0 and the slope not significantly different from 1 , the estimated parameters were considered unbiased (Lactin et al. 1995). The days to emergence for D. radicum from Fort Whyte (2004 2005 experiment) were compared with predicted days using the model developed for D. radicum from Carman (2005-2006 experiment).

\section{Predicting spring emergence in the field}

To place the laboratory results in a field context, meteorological data were used to estimate soil temperature at Prince Albert, Saskatchewan $\left(53^{\circ} 12^{\prime} \mathrm{N}, 105^{\circ} 45^{\prime} \mathrm{W}\right)$, and Carberry, Manitoba $\left(49^{\circ} 52^{\prime} \mathrm{N}, 99^{\circ} 22^{\prime} \mathrm{W}\right)$, from 2002 to 2006 and the soil-temperature data were used to predict spring emergence of each population, using the development-rate model. Daily maximum and minimum air temperatures, rainfall, and total precipitation (Environment Canada 2002) were used to estimate daily mean soil temperature at $5 \mathrm{~cm}$ depth with the soil-temperature algorithm in the modified versatile soil moisture budget (Akinremi et al. 1996). Because daily solar radiation for the two sites was required for the versatile soil moisture budget, we estimated this using the Hargreaves formula for calculating solar radiation (Hargreaves and Samani 1982):

$$
R_{s}=K_{R s} R_{a} \sqrt{\left(T_{\max }-T_{\min )}\right)}
$$

where $R_{\mathrm{S}}$ is the daily solar radiation $\left(\mathrm{MJ} \cdot \mathrm{m}^{-2} \cdot \mathrm{d}^{-1}\right), R_{\mathrm{a}}$ is the extraterrestrial radiation $\left(\mathrm{MJ} \cdot \mathrm{m}^{-2} \cdot \mathrm{d}^{-1}\right)$ at the latitude of the site, $K_{R \mathrm{~s}}$ is the adjustment coefficient for interior land mass $\left(0.16^{\circ} \mathrm{C}^{-0.5}\right)$, and $T_{\max }$ and $T_{\min }$ are the daily maximum and minimum air temperature, respectively. The temperature estimates were tested for bias as described in the previous section using the Carberry site, where actual measurements at $5 \mathrm{~cm}$ depth were available for 2003-2006 (O.O. Akinremi, unpublished data), for the period 1 April 30 June of each year.

The estimates of daily mean soil temperature were used to predict the proportion of development of $D$. radicum and $A$. bilineata completed each day, starting on 1 April of each year. For A. bilineata and for each phenotype of each population of $D$. radicum, 500 parameter sets were selected for the equation

$$
R(T)=R_{m} e^{\left[-\frac{1}{2}\left(\frac{T-T_{m}}{T_{\sigma}}\right)^{2}\right]}+\varepsilon
$$

where $\varepsilon$ is a random error term. For each parameter set, random normal values were drawn for $R_{\mathrm{m}}, T_{\mathrm{m}}$, and $T_{\sigma}$ using the fitted parameter estimates from the model and their corresponding standard error (SE). Random normal values of $\varepsilon$ were also drawn, with mean 0 and SE derived from the error mean square 
for the model. The 500 parameter sets were applied to the soil-temperature data and the cumulative proportions of emergence completed per day used to provide 500 estimates of day of emergence at each location for $A$. bilineata and each $D$. radicum phenotype. Percentiles for day of emergence of A. bilineata were estimated directly; those for D. radicum populations were estimated after combining the early- and late-phenotype estimates, weighted by their proportion of occurrence in each population. Proportions of phenotype occurrence for London and Shellbrook were averages of the two years of data from these locations. For simulated soil temperatures for Carberry, the phenotype compositions of the Fort Whyte and Carman samples were averaged to represent the Manitoba population of $D$. radicum.

\section{Results}

\section{Temperature and development rate}

In both 2004-2005 and 2005-2006 the proportion of $D$. radicum emerging was higher for insects from London than for insects from the prairie populations (Fig. 1). Emergence of A. bilineata was low in both years and for both periods of exposure to $1{ }^{\circ} \mathrm{C}$, especially at the lower treatment temperatures (Fig. 1).

There were two phenotypes (early and late) in the $D$. radicum populations. If $D$. radicum from all sources were considered to be a single population, the breakpoint between the two phenotypes that gave the highest mean corrected $r^{2}$ was $255 \mathrm{DDC}_{4}$. Estimating separate parameters for the two phenotypes using this breakpoint significantly improved the fit of the model ( $a$ in Table 2 ) over that of a model in which no phenotypes were distinguished.

A model with separate parameter estimates for each population, based on a breakpoint of $255 \mathrm{DDC}_{4}$, was not as good a fit to the data as a model using the same parameter estimates but the most appropriate breakpoint for each population ( $b$ in Table 2 ). These breakpoints were $224 \mathrm{DDC}_{4}$ for the London population and $280 \mathrm{DDC}_{4}$ for the prairie populations (Fig. 2). On the basis of these criteria, the early phenotype composed $71 \%$ of 210 individuals that emerged in 2004-2005 and $89 \%$ of
Fig. 1. Percent emergence at different temperatures and after different periods of cold exposure in 2004-2005 and 2005-2006 experiments on Delia radicum from London, Ontario $(a)$; D. radicum from Shellbrook, Saskatchewan (b); D. radicum from Fort Whyte (2004-2005) and Carman, Manitoba (2005-2006) (c); and Aleochara bilineata from Manitoba $(d)$. Emergence was based on the number of insects emerging divided by the number in each treatment, multiplied by 100; for field-collected D. radicum, the number of parasitoids that emerged was subtracted from the divisor.

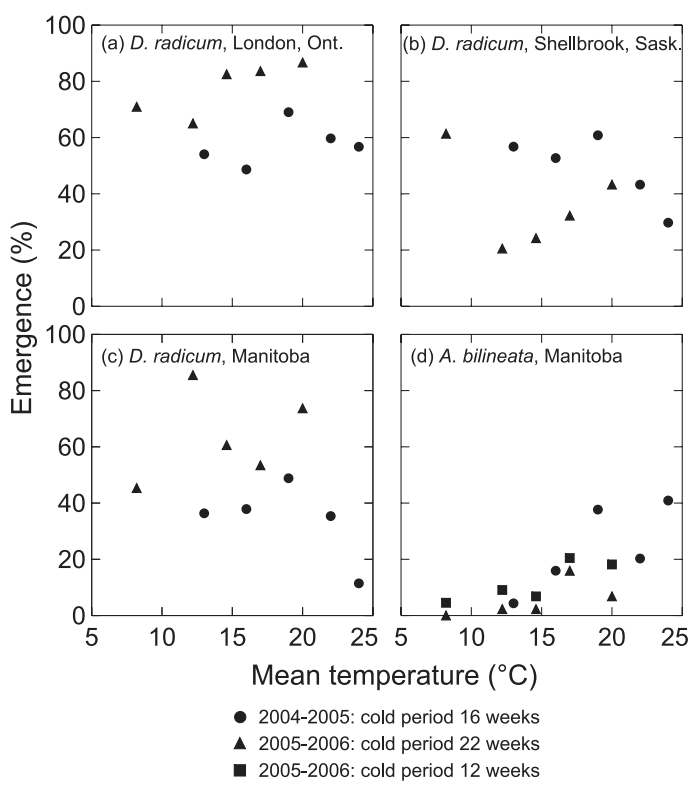

244 individuals that emerged in 2005-2006 in the London population. In the Shellbrook population, $32 \%$ of 183 in $2004-2005$ and $45 \%$ of 124 in 2005-2006 were early phenotype. Of the $234 \mathrm{D}$. radicum from Fort Whyte in the 2004-2005 experiment, 31\% were early phenotype. The Carman population in the 2005 2006 experiment (N.B. with 'en dash' between the years, instead of the normal dash. en dash does not seem to be available in Adobe) had the smallest proportion of early phenotype: $23 \%$ of 230 .

Estimating distinct parameters for the late phenotype for each population yielded a significantly better fit than estimating a single set of parameters that were common to all populations. However, using separate parameters for the late phenotype for the two prairie populations was not significantly better 
Table 2. Error sum of squares $\left(\mathrm{SS}_{\text {error }}\right)$ and degrees of freedom $\left(\mathrm{df}_{\text {error }}\right)$ for models relating rate of development of Delia radicum from London, Ontario, and the "prairies" (Shellbrook, Saskatchewan, and Carman, Manitoba) to temperature.

\begin{tabular}{|c|c|c|c|c|c|}
\hline & Model & $\mathrm{SS}_{\text {error }}{ }^{a}$ & $\mathrm{df}_{\text {error }}$ & Numerator & $F_{\mathrm{df}}^{b}$ \\
\hline \multicolumn{6}{|l|}{$a$} \\
\hline 1 & All $D$. radicum, one phenotype & 0.253156 & 577 & & \\
\hline 2 & $\begin{array}{l}\text { Early and late phenotypes separated } \\
\text { at breakpoint } 255 \mathrm{DDC}_{4}\end{array}$ & 0.039589 & 573 & $a: 1-2$ & $F_{4,573}=772.8^{* * *}$ \\
\hline \multicolumn{6}{|c|}{ 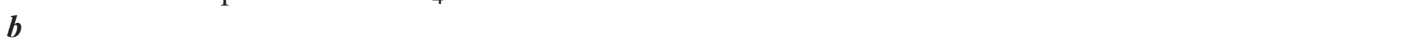 } \\
\hline 1 & $\begin{array}{l}\text { All } D \text {. radicum, } 255 \mathrm{DDC}_{4}, \\
\text { population-specific parameters }\end{array}$ & 0.027299 & 561 & & \\
\hline 2 & $\begin{array}{l}\text { Population-specific breakpoints, } \\
\text { population-specific parameters } \\
\text { based on } 255 \mathrm{DDC}_{4}\end{array}$ & .026797 & 559 & $b: 1-2$ & $F_{2,559}=5.2 *$ \\
\hline \multicolumn{6}{|c|}{ 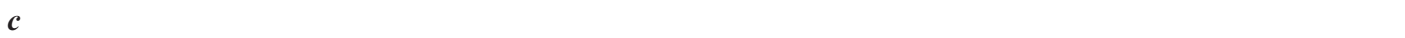 } \\
\hline 1 & $\begin{array}{l}\text { All } D \text {. radicum, population-specific } \\
\text { breakpoints and parameters }\end{array}$ & 0.025287 & 559 & & \\
\hline 2 & Common parameters for late phenotype & 0.027773 & 565 & $c: 2-1$ & $F_{6,559}=9.16^{* * *}$ \\
\hline 3 & $\begin{array}{l}\text { Common parameters for late phenotype } \\
\text { from the prairies }\end{array}$ & 0.025335 & 562 & $c: 3-1$ & $F_{3,559}=0.35$ \\
\hline \multicolumn{6}{|c|}{ 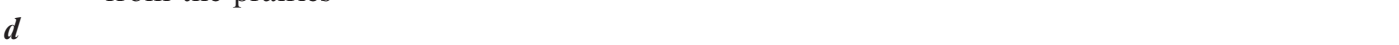 } \\
\hline 1 & $\begin{array}{l}\text { All } D \text {. radicum, population-specific } \\
\text { breakpoint and early-phenotype } \\
\text { parameters, late-phenotype parameters } \\
\text { common for the prairies }\end{array}$ & 0.025335 & 562 & & \\
\hline 2 & Common parameters for early phenotype & 0.039156 & 568 & $d: 2-1$ & $F_{6,562}=51.10^{* * *}$ \\
\hline 3 & $\begin{array}{l}\text { Common parameters for early phenotype } \\
\text { from the prairies }\end{array}$ & .025602 & 565 & $d: 3-1$ & $F_{3,562}=1.97$ \\
\hline
\end{tabular}

${ }^{a}$ Used in $F$-ratio tests to determine whether a model fit the data better with early and late phenotypes $(a)$, populationspecific breakpoints $(b)$, or population-specific model parameters $\left(R_{\mathrm{m}}, T_{\mathrm{m}}, T_{\sigma}\right)(c$ and $d)$.

${ }^{b} F$ statistics denote comparisons of a difference in MSerror (N.B. error could be in subscripts) (identified by line numbers in the numerator column), with MSerror for the model with the lowest $\mathrm{df}_{\text {error }}$ in the same section of the table $(a, b, c$, or $d)(*, P<$ $0.05 ; * *, P<0.01 ; * *, P<0.001)$.

than using pooled estimates for these populations ( $c$ in Table 2). Similarly, estimating separate parameters for each population for the early phenotype improved the model's fit relative to using a single set of early-phenotype parameters but not to using pooled parameter estimates for the two prairie populations ( $d$ in Table 2). Thus, the final model has common parameter estimates (Table 3) and breakpoints for the two prairie locations and these differ from those for the London population. The final model with these parameter estimates explained $98.5 \%$ of the (mean-corrected) among-groups sums of squares. The days to emergence predicted by a model with these parameters, and the actual number of days observed, are illustrated for early-phenotype $D$. radicum (Fig. 3) and for late-phenotype $D$. radicum and for $A$. bilineata (Fig. 4).
The developmental-threshold temperature of the early phenotype was nearly the same for the London and prairie D. radicum populations, but the day-degree requirement of the prairie early phenotype was higher by about 50 (Table 3). The developmental threshold temperature for the late phenotype from London was nearly $1{ }^{\circ} \mathrm{C}$ higher than for prairie $D$. radicum (Table 3), making a direct comparison of the day-degree requirement of this phenotype more difficult. However, latephenotype $D$. radicum from prairie populations appeared to require the accumulation of more heat for post-diapause development than did those from London.

The basic model described A. bilineata's development rate as accurately as a model with separate parameters for individuals assigned to 12 and 22 weeks' cold treatment at $1{ }^{\circ} \mathrm{C}$ (basic 
Fig. 2. Observed cumulative emergence of Delia radicum from London, Carman, and Shellbrook at a constant temperature of $14.6{ }^{\circ} \mathrm{C}$ in relation to day-degrees above $4{ }^{\circ} \mathrm{C}\left(\mathrm{DDC}_{4}\right)$ in the 2005-2006 experiment. The broken lines indicate the estimated breakpoints between early and late phenotypes for the London $\left(224 \mathrm{DDC}_{4}\right)$ and prairie $\left(280 \mathrm{DDC}_{4}\right)$ populations.

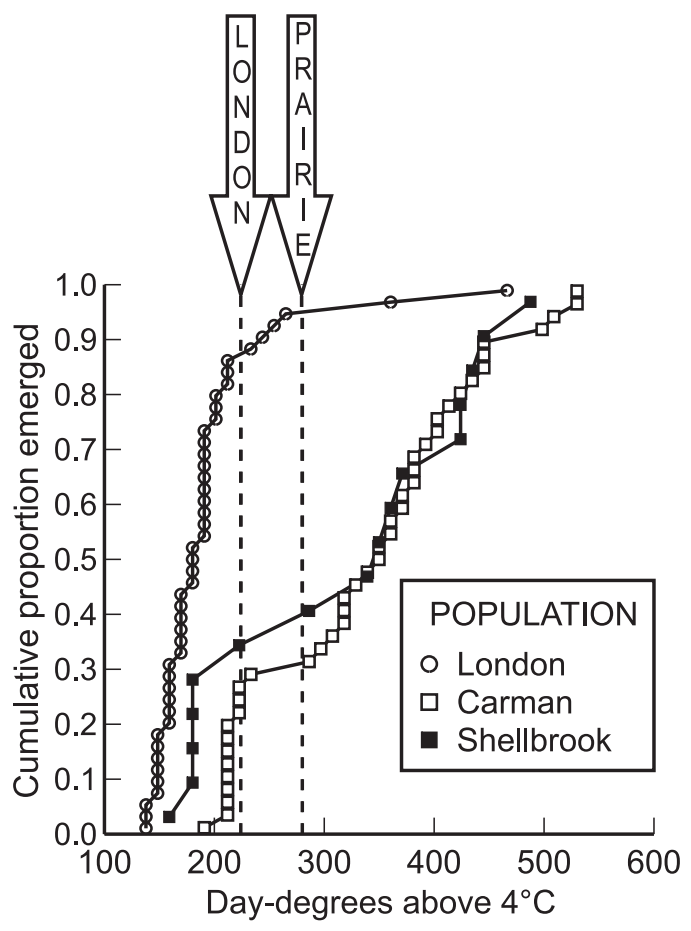

$\mathrm{SS}_{\text {error }}=0.000167287, \mathrm{df}_{\text {error }}=36$; separate $\mathrm{SS}_{\text {error }}=0.000151952, \mathrm{df}_{\text {error }}=33 ; F_{3,33}=1.1$, $P=0.36$ ). The rates of development of the two $A$. bilineata groups were therefore indistinguishable and a single set of the parameters $R_{\mathrm{m}}$, $T_{\mathrm{m}}$, and $T_{\sigma}$ was estimated (Table 3 ). The threeparameter model explained $99.4 \%$ of the means-corrected among-groups sum of squares. Aleochara bilineata had a higher day-degree requirement than did any of the $D$. radicum.

There were six combinations of year, phenotype, and population for which predictions of median observed days to emergence were inaccurate; all were in the 2004-2005 experiment, in which the temperature was gradually increased (Table 4). In four groups, bias was observed; that is, the regression slope was different from 1 or the intercept was different from 0 (Table 4). For A. bilineata, the lack of fit seemed to be at 13 and $16{ }^{\circ} \mathrm{C}$ (Fig. 4), temperatures at which few adults emerged (Fig. 1). For the early $D$. radicum phenotype from Fort Whyte and Shellbrook, the parameters estimated for the prairie $D$. radicum populations consistently underestimated days to emergence (Fig. 3). Of predictions for all populations studied, those for the late $D$. radicum phenotype from London were the poorest, particularly at $24{ }^{\circ} \mathrm{C}$, where days to emergence was overestimated by about 100 (Fig. 4). In addition, there were two late-phenotype groups (Fort Whyte and Shellbrook) in 2004-2005 for which unbiased estimates of days to emergence were obtained but for which $r^{2}$ was relatively low (Table 4); in both cases, days to emergence of the late phenotype was underestimated at $13{ }^{\circ} \mathrm{C}$ and overestimated at $24^{\circ} \mathrm{C}$ (Fig. 4).

Table 3. Estimated parameters for a truncated normal distribution model describing the rate of postdiapause development as a function of temperature, developmental threshold $\left(\mathrm{TH}_{08}\right)$, and day-degree requirement $\left(\mathrm{DD}_{80}\right)$ of early- and late-phenotype Delia radicum populations from London and the "prairies" (Shellbrook and Carman) and a population of Aleochara bilineata from Manitoba.

\begin{tabular}{lccccc}
\hline Population & $R_{\mathrm{m}}$ & $T_{\mathrm{m}}$ & $T_{\sigma}$ & $\mathrm{TH}_{08}$ & $\mathrm{DD}_{80}$ \\
\hline London, early phenotype & $0.1246 \pm 0.0144$ & $28.0343 \pm 2.4896$ & $11.1942 \pm 1.1317$ & 3.1 & 186 \\
Prairies, early phenotype & $0.0841 \pm 0.0061$ & $24.4501 \pm 1.7393$ & $9.6243 \pm 0.9631$ & 3.0 & 237 \\
London, late phenotype & $0.0429 \pm 0.0027$ & $15.6767 \pm 0.4065$ & $4.3857 \pm 0.5340$ & 5.9 & 212 \\
Prairies, late phenotype & $0.0302 \pm 0.0007$ & $17.1913 \pm 0.2267$ & $5.4145 \pm 0.2777$ & 5.1 & 371 \\
Aleochara bilineata & $0.0349 \pm 0.0021$ & $22.5083 \pm 1.2976$ & $7.4820 \pm 0.8420$ & 5.8 & 444 \\
\hline
\end{tabular}

Note: $R_{\mathrm{m}}$ is the maximum development rate, $T_{\mathrm{m}}$ is the temperature at which the rate is maximal, and $T_{\sigma}$ is a shape parameter. All are given as the mean $\pm \mathrm{SE} . \mathrm{TH}_{08}=T_{\mathrm{m}}-2.23 T_{\sigma} . \mathrm{DD}_{80}=T_{\sigma} / 0.482 R_{\mathrm{m}}$ 
Fig. 3. Comparison of predicted and observed times from the end of cold exposure to the start of emergence for early-phenotype Delia radicum from Ontario, Manitoba, and Saskatchewan in two years. The solid curve represents predictions from the model fitted to 2005-2006 data; the extension (broken line) represents predictions beyond the temperature range used to fit the model. The upper and lower boundaries and midline of the boxes at each temperature represent lower and upper quartiles and median observed times, respectively. Whiskers attached to the boxes represent the range of values that fall within $1.5 \times$ the interquartile distance beyond quartiles. Extreme observations are represented by crosses $(\leq 3 \times$ the interquartile distance from the quartile) or circles $(>3 \times$ the interquartile distance from the quartile).
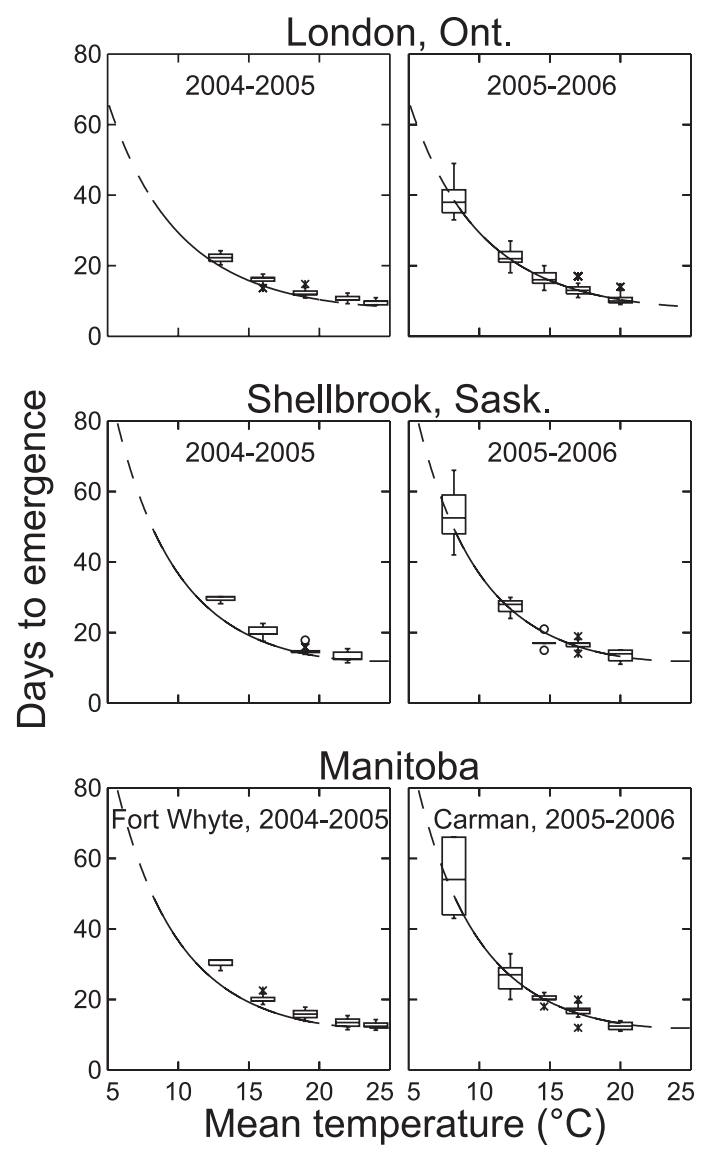

\section{Predicting spring emergence in the field}

Regressions of observed temperature on estimated temperature $5 \mathrm{~cm}$ below the soil surface revealed that much of the variance was explained $\left(r^{2}>0.75\right)$. The intercept of the
Fig. 4. Comparison of predicted and observed times from the end of cold exposure to the start of emergence for late-phenotype Delia radicum from Ontario, Manitoba, and Saskatchewan and for Aleochara bilineata in 2 years (see Fig. 3 for details).
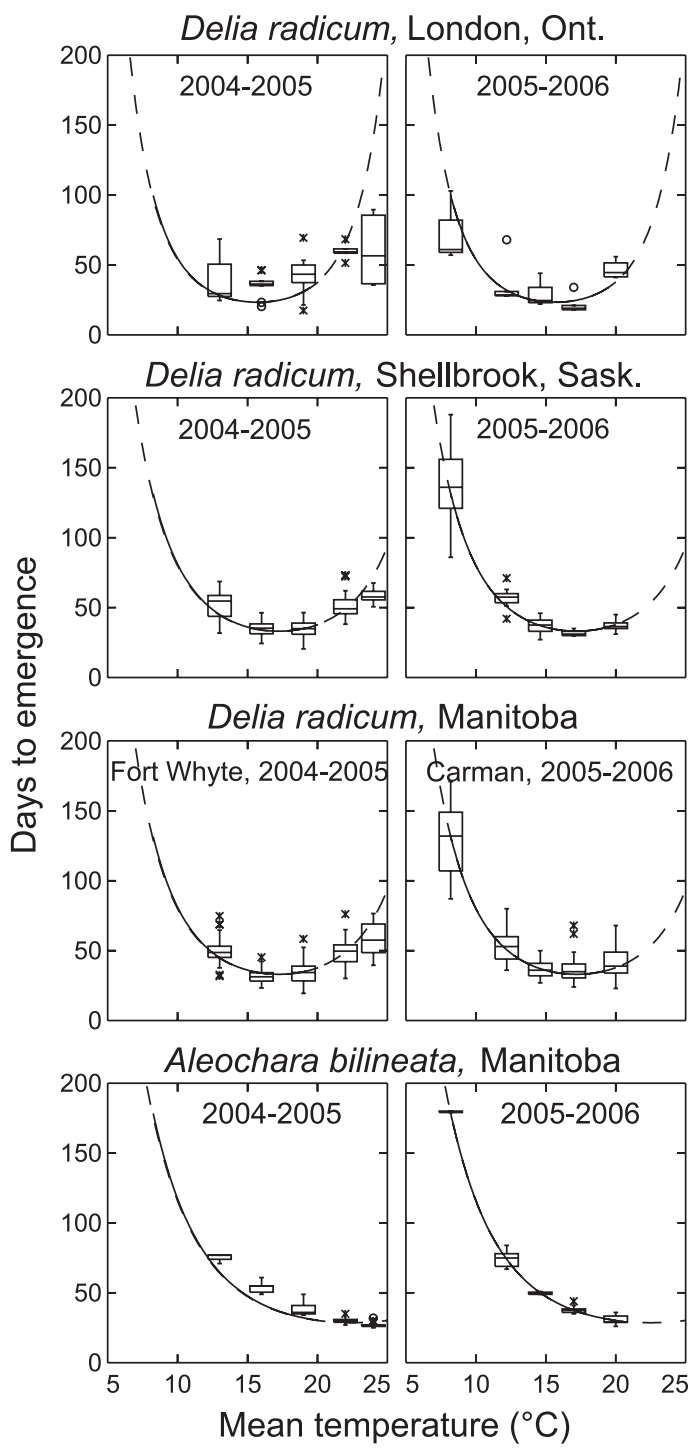

regressions, however, was significantly different from 0 for 2003-2005 but not in 2006; inspection of plots revealed that the versatile soil moisture budget slightly overestimated low temperatures early in the season. As a result, development started 0-4 days earlier in the simulation than was predicted from actual soil temperatures, depending on the year and group. Slope coefficients for these regressions 
Table 4. Statistics for a test of model bias by linear regression of predicted on observed days to emergence, for $n$ temperature treatments for populations of Delia radicum from Manitoba, Ontario, and Saskatchewan and for Aleochara bilineata from Manitoba.

\begin{tabular}{|c|c|c|c|c|c|c|c|c|}
\hline Population & Year & Phenotype & $\begin{array}{c}\text { Adjusted } \\
\text { multiple } r^{2}\end{array}$ & $n$ & Itercept & $P^{a}$ & Slope & $P^{a}$ \\
\hline \multirow{2}{*}{$\begin{array}{l}\text { Aleochara bilineata, } \\
\text { Manitoba }\end{array}$} & 2004-2005 & & 0.962 & 5 & $9.57 \pm 3.01$ & $\mathrm{~ns}$ & $0.69 \pm 0.07$ & $*$ \\
\hline & 2005-2006 & & 0.999 & 5 & $0.94 \pm 0.57$ & ns & $0.99 \pm 0.01$ & ns \\
\hline \multicolumn{9}{|l|}{ Delia radicum } \\
\hline \multirow[t]{2}{*}{ Fort Whyte, Man. } & 2004-2005 & Early & 0.996 & 5 & $-0.10 \pm 0.44$ & ns & $0.82 \pm 0.03$ & $*$ \\
\hline & & Late & 0.774 & 5 & $-5.84 \pm 12.83$ & ns & $1.16 \pm 0.30$ & ns \\
\hline \multirow[t]{2}{*}{ Carman, Man. } & 2005-2006 & Early & 0.997 & 5 & $2.10 \pm 0.74$ & ns & $0.88 \pm 0.06$ & ns \\
\hline & & Late & 0.999 & 5 & $-1.09 \pm 1.31$ & ns & $1.00 \pm 0.02$ & ns \\
\hline \multirow[t]{4}{*}{ London, Ont. } & 2004-2005 & Early & 0.993 & 5 & $-1.20 \pm 0.50$ & ns & $0.89 \pm 0.04$ & ns \\
\hline & & Late & 0.568 & 5 & $123.73 \pm 32.07$ & $*$ & $-2.42 \pm 0.97$ & $*$ \\
\hline & 2005-2006 & Early & 0.999 & 5 & $0.10 \pm 0.35$ & ns & $1.01 \pm 0.02$ & ns \\
\hline & & Late & 0.832 & 5 & $-16.70 \pm 17.03$ & ns & $1.70 \pm 0.44$ & ns \\
\hline \multirow[t]{4}{*}{ Shellbrook, Sask. } & 2004-2005 & Early & 0.994 & $4^{b}$ & $1.67 \pm 0.77$ & ns & $0.71 \pm 0.04$ & $*$ \\
\hline & & Late & 0.541 & 5 & $0.89 \pm 22.46$ & $\mathrm{~ns}$ & $0.97 \pm 0.51$ & ns \\
\hline & 2005-2006 & Early & 0.984 & 5 & $1.69 \pm 1.92$ & ns & $0.90 \pm 0.06$ & ns \\
\hline & & Late & 0.993 & 5 & $1.59 \pm 2.90$ & $\mathrm{~ns}$ & $0.95 \pm 0.04$ & ns \\
\hline
\end{tabular}

${ }^{a} t$ test, $\mathrm{df}=n-2$; "ns", not significantly different from $0 ;{ }^{*}$, significant at the 0.05 level.

${ }^{b}$ No early phenotype emerged at $24{ }^{\circ} \mathrm{C}$.

were indistinguishable from $1(P>0.05)$ in all years except 2003 (slope $=1.19, \mathrm{SE}=0.035 ; t_{75}$ $=5.3, P<0.001)$.

Delia radicum from London were predicted to emerge prior to those from the prairies, at both Carberry and Prince Albert (Fig. 5). At Carberry, predicted median emergence of adult A. bilineata was $13 \pm 0.9$ days (mean \pm SEM) $(n=5)$ after that of Manitoba $D$. radicum and $34 \pm 2.4$ days after that of $D$. radicum from London. At Prince Albert, the predicted median emergence of $A$. bilineata was $16 \pm$ 1.9 days after that of $D$. radicum from Saskatchewan and $33 \pm 2.8$ days after that of D. radicum from London. In both locations, median emergence of $A$. bilineata was predicted to be $9 \pm 1$ days after that of the prevailing late phenotype from prairie populations and much later than that of the majority of flies in the population from London, which was composed mainly of the early phenotype (Fig. 5).

\section{Discussion}

\section{Development of $\boldsymbol{D}$. radicum}

This study is the first to model the temperature dependence of rates of development of
D. radicum on canola in Canada and the first to demonstrate geographic variation in the criterion separating early and late phenotypes of this species. Differences in temperaturedependent development rates between Manitoba and eastern Canadian D. radicum populations have been observed previously (Turnock and Boivin 1997), but given the small geographic scale of such variation in some areas (Finch et al. 1986), we found surprising homogeneity in $D$. radicum from prairie localities as far apart as $700 \mathrm{~km}$.

The timing of a species' seasonal cycle can vary both geographically, if a population from a specific location is better adapted to that area than another, and at the intrapopulation level, in which a population exhibits a range of responses to seasonal change (Danilevsky et al. 1970; Tauber and Tauber 1981). At the intrapopulation level, $D$. radicum phenotypes with rapid, intermediate, and slow development can be readily selected in the laboratory (Finch and Collier 1983; Walgenbach et al. 1993; Biron et al. 1998). It is hypothesized that two phenotypes persist because the early phenotype can complete more generations in warm years and the late phenotype is safer in 
Fig. 5. Predicted cumulative emergence in relation to Julian date for each of 5 years for the London and Manitoba populations of Delia radicum and Aleochara bilineata at Carberry $(a)$ and of the London and Shellbrook populations of D. radicum and A. bilineata at Prince Albert (b).

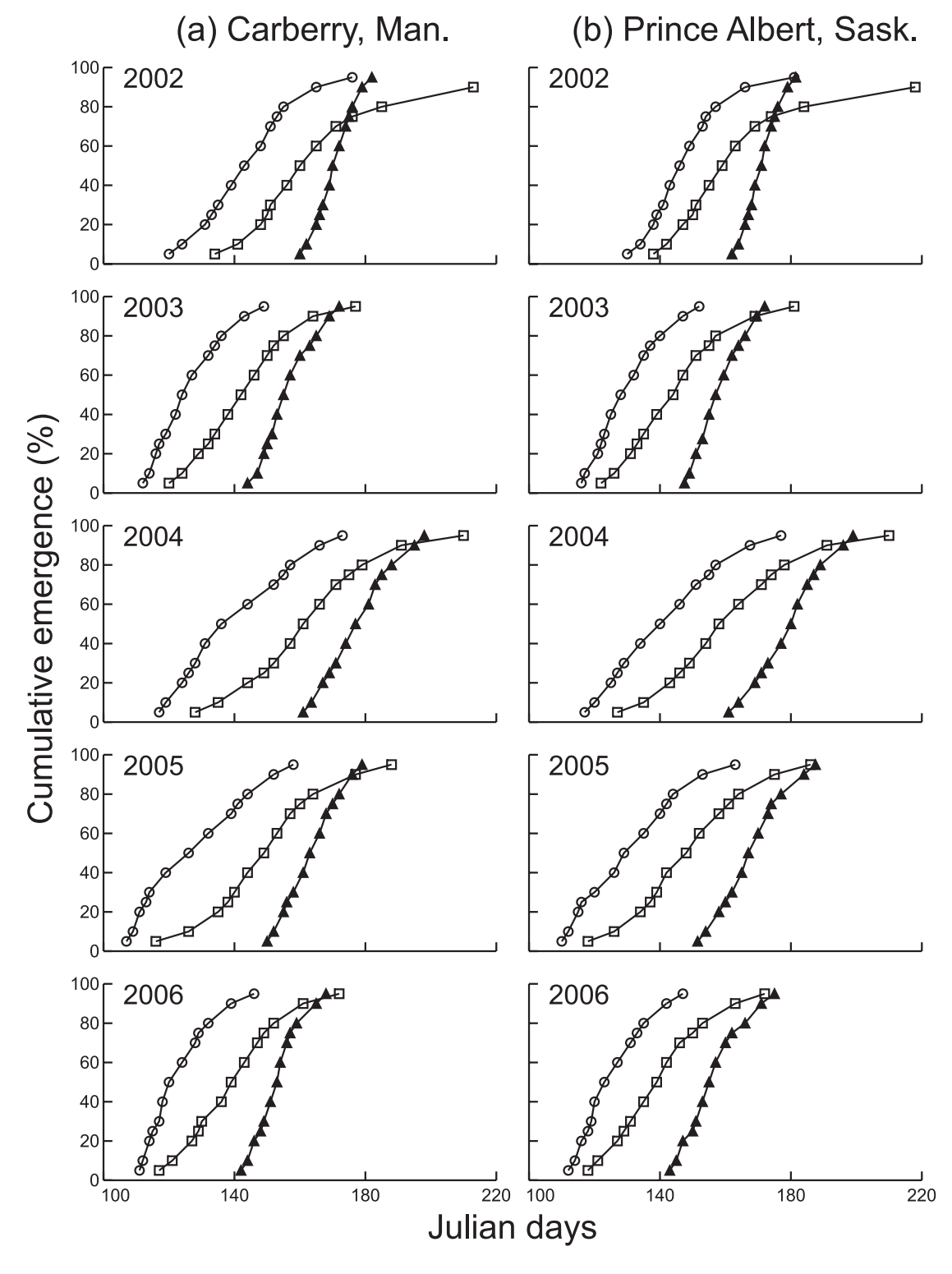
D. radicum London $\ominus$
D. radicum Prairie
A. bilineata

extreme spring weather that may kill earlyemerging adults before they can reproduce (Finch and Collier 1983; Walgenbach et al. 1993; Biron et al. 1998). The positive correlation between the proportion of the early phenotype in a locality and thermal accumulation during the previous growing season supports this hypothesis (Turnock and Boivin 1997). At the geographic level, the relative proportions of the two phenotypes (Finch and Collier 1983, 1985; Finch et al. 1986; Turnock and Boivin 1997) and the developmental response of both phenotypes to temperature (Turnock and Boivin 1997) can vary among 
populations. Either phenotype could be selected naturally to synchronize emergence in spring with the availability of host plants in a particular area (Finch et al. 1986) as well as to respond to local climatic conditions (Turnock and Boivin 1997).

In previous studies a range of breakpoints has been applied to distinguish early and late phenotypes. This study demonstrates that the most appropriate criterion to use depends upon the population being studied. Specifically, samples collected around canola roots in Manitoba and Saskatchewan in our 20052006 experiment had the same breakpoint, which was higher than that for collections from the roots of rutabaga in London. If this difference is genetically based, selection pressure on prairie populations has favoured protracted emergence of the early phenotype, less protracted emergence of the late phenotype, or both.

For both early and late phenotypes, selection pressure on prairie populations has been uniform enough to cause responses of development to temperature to be the same over a large geographic area. These responses are distinct from those of corresponding phenotypes from London. The most obvious interpretation is that the most favourable time of emergence in spring depends on local availability of host plants. The principal host plant on the prairies is canola, and in the early 1980s gravid female D. radicum were present well before canola was in a stage preferred for oviposition (Griffiths 1986a). Perhaps emergence has become progressively later over the intervening years, thus minimizing the time female $D$. radicum spend waiting to lay eggs. Differences in climate may also favour differences in responses to temperature. London is about $7^{\circ}$ south of the prairie areas studied, and the growing season starts about 2 weeks later and the frost-free period is $30-40$ days shorter at the prairie locations than in London (Chapman and Brown 1966). Early-phenotype females would be more likely to die from weather-associated causes before laying eggs on the prairies than in the Ontario location. Both phenotypes from the prairies required more time to emerge than did the corresponding phenotypes from London, and also, the proportions of individuals in the prairie populations that were of the late phenotype were higher.

Turnock and Boivin (1997) studied D. radicum collected from rutabaga from the Canadian prairies and London using methods similar to those used here. Too few London individuals were of the late phenotype for analysis in their study, and the London early phenotype had a higher developmental threshold $\left(\mathrm{TH}_{08}=5.0\right)$ and lower day-degree requirement $\left(\mathrm{DD}_{80}=160\right)$ than in our study. The higher threshold may be accounted for in part by their use of different criteria to separate the phenotypes, and therefore by their inclusion as early phenotype of some individuals that perhaps would have been better considered late. The developmental threshold and day-degree requirement of our early-phenotype $D$. radicum from canola in Manitoba and Saskatchewan are similar to those of early D. radicum from Brassica vegetable plants from Winnipeg, Manitoba $\left(\mathrm{TH}_{08}=3.3, \mathrm{DD}_{80}=\right.$ 246), reported in Turnock and Boivin (1997). Our prairie late phenotype had a higher developmental threshold and day-degree requirement than late $D$. radicum from Winnipeg reported in Turnock and Boivin (1997) $\left(\mathrm{TH}_{08}=4.4, \mathrm{DD}_{80}=316\right)$. Our prairie latephenotype $D$. radicum had an estimated developmental threshold similar to that of late D. radicum from England $\left(\mathrm{TH}_{08}=5.0, \mathrm{DD}_{80}=\right.$ 538) and Prince Edward Island $\left(\mathrm{TH}_{08}=5.0\right.$, $\mathrm{DD}_{80}=530$ ) (Turnock and Boivin 1997), but the day-degree requirement was much lower. Therefore, our prairie late-phenotype $D$. radicum did not emerge as late as those of some other populations and were similar to North Carolina (Walgenbach et al. 1993) and certain English (Finch et al. 1986) populations. The assumption that individuals in a $D$. radicum population will fall into one of two well-defined and universal phenotypes is a good first approximation, but is no doubt an oversimplification.

Data from the 2004-2005 experiment were not always well explained by the model developed using the 2005-2006 results, and this could be attributable to three methodological differences between the experiments: rate of temperature increase, duration of cold treatment, and range of temperatures used. 
The rate at which post-diapause $D$. radicum pupae develop depends on the speed of the transition from low to higher temperatures (Hemachandra 2004). In this study, gradually raising the temperature caused earlyphenotype $D$. radicum and $A$. bilineata to develop more slowly than predicted. The duration of cold treatment is expected to affect the proportion of pupae that complete diapause and can begin post-diapause development when the temperature is raised. At $0{ }^{\circ} \mathrm{C}$, diapause is complete in about $60 \%$ of D. radicum individuals after 16 weeks, and this proportion reaches a maximum after 22 weeks (Collier and Finch 1983). Incomplete diapause would cause days to development to be higher than expected. As well, in the 2004-2005 experiment, two of the temperatures used were 22 and $24{ }^{\circ} \mathrm{C}$; temperatures above $21^{\circ} \mathrm{C}$ cause death or delayed development of pupae (Finch and Collier 1985; Johnsen et al. 1990), although this phenomenon seems to be specific to certain populations (Turnock and Boivin 1997). If mortality is an important factor, only rapidly developing individuals would emerge, giving the impression that development time had been overestimated. Also, no data collected above $20{ }^{\circ} \mathrm{C}$ were used in developing the model. Overestimation due to extrapolation of development rates at 22 and $24{ }^{\circ} \mathrm{C}$ (rather than to heat injury) is a reasonable explanation for deviations from predictions for A. bilineata in our 2004-2005 experiment because survival of $A$. bilineata was greater at higher temperatures.

\section{Synchronization of $A$. bilineata emergence with prey availability}

Adult A. bilineata are generally believed to emerge too late in spring to feed on $D$. radicum eggs laid by the overwintered generation (Read 1962; Jonasson 1994), even though in the laboratory, adult $A$. bilineata will eat immediately after emergence if provided with food. In southern Ontario, adult Aleochara (predominantly $A$. bilineata) emerged "no later than two weeks" (Nair and McEwen 1975, p. 349) after overwintered D. radicum in 1971 and about three weeks later than their hosts in 1972 (Nair and McEwen 1975), considerably later than the start of oviposition.
We used models of soil temperature at a typical depth for $D$. radicum pupation because there are insufficient observations of temperatures of prairie soils at the time of postdiapause development. Our models tended to overestimate soil temperatures near the time of snowmelt, when temperatures are low and increments of development minuscule. Thus, we expected there to be little influence of this bias on the predicted dates of emergence. Although the distributions of predicted days to emergence respond to variation in development rates detected in our modelling procedure, they do not capture variation due to differences in the pupal environment related to soil type, moisture level, or depth of pupae in soil. However, they do provide a way of assessing the relative time of emergence of insects experiencing the same environmental conditions. The predicted intervals between emergence of $A$. bilineata and prairie $D$. radicum suggest that emergence of A. bilineata on the prairies is well synchronized with availability of prey. Under optimal conditions, four or five days elapse between emergence of adult female $D$. radicum and commencement of oviposition (Finch 1974), and the oviposition rate is high for two-three weeks thereafter (Swailes 1961; Finch and Coaker 1969). Eggs hatch four-five days after oviposition (Finch and Coaker 1969). Thus, at the time of $A$. bilineata emergence, D. radicum eggs would recently have become available, and would be available for several weeks.

Emergence-cage studies in prairie canola stubble have shown that overwintered A. bilineata (Broatch et al. 2008) start to emerge about one week after peak $D$. radicum emergence in mid-June (Broatch et al. 2006), and most $A$. bilineata emerge two-three weeks following the $D$. radicum peak. Traps used in current-year crops in the same area, however, show both species to be present prior to their appearance in cages, and in one of two years for which comparable data have been published, the periods during which the two species were most active were coincident (Broatch et al. 2006, 2008). Broatch et al. (2008) argue that, as a predator, A. bilineata is better synchronized with the availability of of $D$. radicum eggs on the prairies than elsewhere. 
The current study also shows that emergence of adult $A$. bilineata on the prairies is well synchronized with the availability of $D$. radicum eggs. The predominance of the late phenotype and the uniformity of the temperature dependence of rates of development of $D$. radicum on the prairies may have made synchronization of predator with prey more likely. Selection on prairie $D$. radicum to emerge earlier (and reduce the risk of egg predation by $A$. bilineata) seems to have been less strong than selection favouring later emergence, reduced weather-induced mortality, and better synchronization with host plants. Although adult $A$. bilineata potentially live much longer than the period required for a $D$. radicum egg to develop into a pupa (Read 1962), we expect that selection on $A$. bilineata development rates would tend to favour synchronization with the availability of host puparia rather than D. radicum eggs. Furthermore, we expect the strength of this selection to depend upon the importance of $D$. radicum eggs relative to other types of prey and of $D$. radicum puparia relative to those of other host species. Where early-phenotype $D$. radicum predominate and there are many potential host plants for $D$. radicum, springtime synchronization of $A$. bilineata predation with the availability of $D$. radicum eggs may remain imperfect.

\section{Acknowledgements}

We thank B. Bellefeuille and A. Leroux for technical assistance. Funding was provided by the Government of Manitoba, the Natural Sciences and Engineering Research Council of Canada, Agriculture and Agri-Food Canada, the University of Manitoba, the Western Grains Research Foundation, and the Canola Council of Canada.

\section{References}

Akinremi, O.O., McGinn, S.M., and Barr, A.G. 1996. Simulation of soil moisture and other components of the hydrological cycle using a water budget approach. Canadian Journal of Soil Science, 75: 133-142.

Biron, D.G., Langlet, X., Boivin, G., and Brunel, E. 1998. Expression of early and late-emerging phenotypes in both diapausing and nondiapausing Delia radicum (L.) pupae. Entomo- logia Experimentalis et Applicata, 87: 119-124. doi:10.1046/j.1570-7458.1998.00313.x.

Biron, D.G., Coderre, D., Boivin, G., Brunel, E., and Nénon, J.P. 2002. Genetic variability and expression of phenological and morphological differences in populations of Delia radicum (Diptera: Anthomyiidae). The Canadian Entomologist, 134: 311-327. doi:10.4039/Ent134311-3.

Bracken, G.K. 1988. Seasonal occurrence and infestation potential of cabbage maggot, Delia radicum (L.) (Diptera: Anthomyiidae), attacking rutabaga in Manitoba as determined by captures of females in water traps. The Canadian Entomologist, 120: 609-614. doi:10.4039/Ent120609-7.

Broatch, J.S., Dosdall, L.M., Clayton, G.W., Harker, K.N., and Yang, R.C. 2006. Using degree-day and logistic models to predict emergence pattern and seasonal flights of the cabbage maggot and seed corn maggot (Diptera: Anthomyiidae) in canola. Environmental Entomology, 35: 1166-1177. doi:10.1603/0046-225X(2006)35 [1166:UDALMT]2.0.CO;2.</jrn $>$.

Broatch, J.S., Dosdall, L.M., Clayton, G.W., Harker, K.N., and Yang, R.C. 2008. Emergence and seasonal activity of the entomophagous rove beetle Aleochara bilineata (Coleoptera: Staphylinidae) in canola in western Canada. Environmental Entomology, 37: 1451-1460. PMID: 19161688 doi:10.1603/0046-225X-37.6.1451.

Brooks, A.R. 1951. Identification of the root maggots (Diptera: Anthomyiidae) attacking cruciferous crops in Canada, with notes on biology and control. The Canadian Entomologist, 83: 109-120. doi:10.4039/Ent83109-5.

Chapman, L.J., and Brown, D.M. 1966. The Canada land inventory report 3 : the climates of Canada for agriculture. Department of Forestry and Rural Development, Ottawa, Ontario.

Collier, R.H., and Finch, S. 1983. Effects of temperature and duration of low temperatures in regulating diapause development of the cabbage root fly (Delia radicum). Entomologia Experimentalis et Applicata, 34: 193-200. doi:10. 1007/BF00338669.

Collier, R.H., Finch, S., and Anderson, M. 1989a. Laboratory studies on late-emergence in the cabbage root fly (Delia radicum). Entomologia Experimentalis et Applicata, 50: 233-240. doi:10. 1007/BF00341172.

Collier, R.H., Finch, S., and Anderson, M. $1989 b$. Oxygen uptake by pupae of early- and lateemerging biotypes of the cabbage root fly Delia radicum L. Functional Ecology, 3: 613-616. doi:10.2307/2389576.

Danilevsky, A.S., Goryshin, N.I., and Tyshchenko, V.P. 1970. Biological rhythms in terrestrial arthropods. Annual Review of Entomology, 15: 201-244. doi:10.1146/annurev.en.15.010170. 001221.

Environment Canada. 2002. Canadian climate data [online]. Available from http://www.climate. 
weatheroffice.ec.gc.ca/climateData/canada_e.html [accessed October 2007].

Finch, S. 1974. Feeding and associated behaviour of the adult cabbage root fly Erioschia brassicae (Bch.) (Dipt., Anthomyiidae) under laboratory conditions. Bulletin of Entomological Research, 63: 661-671. doi:10.1017/S0007485300047891.

Finch, S., and Coaker, T.H. 1969. A method for the continuous rearing of the cabbage root fly Erioschia brassicae (Bch.) and some observations on its biology. Bulletin of Entomological Research 58: 619-627. doi:10.1017/S0007485300057345.

Finch, S., and Collier, R.H. 1983. Emergence of flies from overwintering populations of cabbage root fly pupae. Ecological Entomology, 8: 29-36. doi:10.1111/j.1365-2311.1983.tb00479.x.

Finch, S., and Collier, R.H. 1985. Laboratory studies on aestivation in the cabbage root fly (Delia radicum). Entomologia Experimentalis et Applicata, 38: 137-143. doi:10.1007/BF00361924.

Finch, S., Collier, R.H., and Skinner, G. 1986. Local population differences in emergence of cabbage root flies from south-west Lancashire: implications for pest forecasting and population divergence. Ecological Entomology, 11: 139-145. doi:10.1111/j.1365-2311.1986.tb00288.x.

Finch, S., Bromand, B., Brunel, E., Bues, M., Collier, R.H., Dunne, R., et al. 1988. Emergence of cabbage root flies from puparia collected throughout northern Europe. In Progress on Pest Management in Field Vegetables: Proceedings of the Commission of the European Communities/ International Organization for Biological Control Experts' Group Meeting, Rennes, France 20-22 November 1985. Edited by R. Cavalloro and C. Pelerents. A.A. Balkema, Rotterdam, The Netherlands. pp. 33-36.

Gallant, A.R. 1987. Nonlinear statistical models. John Wiley and Sons, New York.

Griffiths, G.C.D. 1986a. Phenology and dispersion of Delia radicum (L.) (Diptera: Anthomyiidae) in canola fields at Morinville, Alberta. Quaestiones Entomologicae, 22: 29-50.

Griffiths, G.C.D. 1986b. Relative abundance of the root maggots Delia radicum (L.) and D. floralis (Fallen) (Diptera: Anthomyiidae) as pests of canola in Alberta. Quaestiones Entomologicae, 22: 253-260.

Griffiths, G.C.D. 1991. Cyclorrhapha II (Schizophora: Calyptratae) Anthomyiidae. Vol. 8. Part 2. No. 8. E. Schweizerbart'sche Verlagsbuchhandlung (Naegele u. Obermiller), Stuttgart, Germany.

Hargreaves, G.H., and Samani, L.C. 1982. Estimating potential evapotranspiration. Journal of the Irrigation and Drainage Division, 108: 225230.

Hemachandra, K.S. 2004. Parasitoids of Delia radicum (Diptera: Anthomyiidae) in canola: assessment of potential agents for classical biological control. Ph.D. thesis, University of Manitoba, Winnipeg, Manitoba.

Hemachandra, K.S., Holliday, N.J., Mason, P.G., Soroka, J.J., and Kuhlmann, U. 2007. Comparative assessment of the parasitoid community of Delia radicum in the Canadian prairies and Europe: a search for classical biological control agents. Biological Control, 43: 85-94. doi:10.1016/ j.biocontrol.2007.07.005.

Hughes, R.D. 1960. Induction of diapause in Erioschia brassicae Bouche (Dipt., Anthomyiidae). Journal of Experimental Biology, 37: 218223.

Johansen, T.J., and Meadow, R. 2006. Population differences in emergence of brassica root flies (Diptera: Anthomyiidae). Environmental Entomology, 35: 1161-1165. doi:10.1603/0046-225X (2006)35[1161:PDIEOB]2.0.CO;2.

Johnsen, S., Guttierez, A.P., and Freuler, J. 1990. The within season population dynamics of the cabbage root fly (Delia radicum [L.]). A simulation model. Mitteilungen der schweizerischen entomologische Gesellschaft, 63: 451-463.

Jonasson, T. 1994. Parasitoids of Delia root flies in brassica vegetable crops: coexistence and niche separation in two Aleochara species (Coleoptera: Staphylinidae). Norwegian Journal of Agricultural Sciences Supplement, 16: 379-386.

Kvalseth, T.O. 1985. Cautionary note about $R^{2}$. The American Statistician, 39: 279-285. doi:10.2307/ 2683704.

Lactin, D.J., Holliday, N.J., Johnson, D.L., and Craigen, R. 1995. Improved rate model of temperature-dependent development by arthropods. Environmental Entomology, 24: 68-75.

Lamb, R.J. 1992. Developmental rate of Acyrthosiphon pisum (Homoptera: Aphididae) at low temperatures: implications for estimating rate parameters for insects. Environmental Entomology, 21: 10-19.

Nair, K.S.S., and McEwen, F.L. 1975. Ecology of the cabbage maggot, Hylemya brassicae (Diptera: Anthomyiidae), in rutabaga in southwestern Ontario, with some observations on other root maggots. The Canadian Entomologist, 107: 343-354. doi:10.4039/Ent107343-4.

Read, D.C. 1962. Notes on the life history of Aleochara bilineata (Gyll.) (Coleoptera: Staphylinidae), and on its potential value as a control agent for the cabbage maggot, Hylemya brassicae (Bouche) (Diptera: Anthomyiidae). The Canadian Entomologist, 94: 417-424. doi:10.4039/ Ent94417-4.

Read, D.C. 1969. Rearing the cabbage maggot with and without diapause. The Canadian Entomologist, 101: 725-737. doi:10.4039/Ent101725-7.

Sokal, R.R., and Rohlf, F.J. 1995. Biometry: the principles and practices of statistics in biological research. 3rd ed. W.H. Freeman and Company, New York. 
Soroka, J.J., Kuhlmann, U., Floate, K.D., Whistlecraft, J., Holliday, N.J., and Boivin, G. 2002. Delia radicum (L.), cabbage maggot (Diptera: Anthomyiidae). In Biological control programmes in Canada. Edited by P.G. Mason and J.T. Huber. CABI Publishing, Wallingford, United Kingdom. pp. 99-104.

Soroka, J.J., Dosdall, L.M., Olfert, O.O., and Seidle, E. 2004. Root maggots (Delia spp., Diptera: Anthomyiidae) in prairie canola (Brassica napus $\mathrm{L}$. and $B$. rapa $\mathrm{L}$.): spatial and temporal surveys of root damage and prediction of damage levels. Canadian Journal of Plant Science, 84: 1171-1182.

Southwood, T.R.E., and Siddorn, J.W. 1965. The temperature beneath insect emergence traps of various types. Journal of Animal Ecology, 34: 581-585. doi: $10.2307 / 2451$.

Swailes, G.E. 1961. Laboratory studies on mating and oviposition of Hylemya brassicae (Bouché) (Diptera: Anthomyiidae). The Canadian Entomologist 93: 940-943. doi:10.4039/Ent93940-10.

Tauber, C.A., and Tauber, M.J. 1981. Insect seasonal cycles: genetics and evolution. Annual Review of Ecology and Systematics, 12: 281-308. doi:10.1146/annurev.es.12.110181.001433.

Taylor, F. 1981. Ecology and evolution of physiological time in insects. The American Naturalist, 117: 1-23. doi:10.1086/283683.
Turnock, W.J., and Boivin, G. 1997. Inter- and intrapopulation differences in the effects of temperature on postdiapause development of Delia radicum. Entomologia Experimentalis et Applicata, 84: 255265. doi:10.1046/j.1570-7458.1997.00223.x.

Turnock, W.J., Jones, T.H., Reader, P.M. 1985. Effects of cold stress during diapause on the survival and development of Delia radicum (Diptera: Anthomyiidae) in England. Oecologia, 67: 506-510. doi:10.1007/BF00790021.

Turnock, W.J., Boivin, G., and Whistlecraft, J.W. 1995. Parasitism of overwintering puparia of the cabbage maggot Delia radicum (L.) (Diptera: Anthomyiidae), in relation to host density and weather factors. The Canadian Entomologist, 127: 535-542. doi:10.4039/Ent127535-4.

Wadsworth, J.T. 1915. On the life-history of Aleochara bilineata, Gyll., a staphylinid parasite of Chortophila brassicae, Bouché. Journal of Economic Biology, 10: 1-17.

Walgenbach, J.F., Eckenrode, C.J., and Smith, R.W. 1993. Emergence patterns of Delia radicum (Diptera: Anthomyiidae) populations from North Carolina and New York. Environmental Entomology, 22: 559-566.

Whistlecraft, J.W., Harris, C.R., Tolman, J.H., and Tomlin, A.D. 1985. Mass-rearing technique for Aleochara bilineata (Coleoptera: Staphylinidae). Journal of Economic Entomology, 78: 995-997. 